\title{
Trabalho Doméstico Remunerado e Covid-19: aprofundamento das vulnerabilidades EM UMA OCUPAÇÃO PRECARIZADA ${ }^{1,2}$
}

Carolina Tokarski ${ }^{3}$

Luana Pinheiro ${ }^{4}$

\section{INTRODUÇÃO}

Em 11 de março de 2020, a Organização Mundial da Saúde (OMS) caracterizou o surto provocado pela doença causada pelo novo coronavírus, a Covid-19, como uma pandemia, uma vez que ela atingiu rapidamente um contágio mundial. Desde entáo, a única forma que tem se mostrado eficaz no enfrentamento da propagação do vírus sáo as medidas de isolamento social, adotadas em quase todos os países.

No Brasil, essas medidas vêm sendo adotadas de maneira heterogênea em cada estado, como o uso obrigatório de máscaras e o fechamento de escolas e de diversos tipos de estabelecimentos comerciais. O Decreto no 10.282, de 20 de março de 2020, estabeleceu os serviços públicos e as atividades essenciais que devem funcionar mesmo durante a vigência do distanciamento social. Com o prolongamento da pandemia no país ${ }^{5}$ e dos seus efeitos (há um platô de cerca de 1 mil mortes por dia), as medidas de isolamento têm sido flexibilizadas e boa parte das interações sociais em estabelecimentos diversos já vem sendo permitida - desde que, teoricamente, com uma série de medidas de proteção -, com algumas poucas exceçóes, como o funcionamento de escolas e de shows/espetáculos culturais presenciais.

Diversas pesquisas têm demonstrado que os impactos da pandemia acontecem de modo diferente na população brasileira, sendo as populaçôes historicamente vulnerabilizadas as mais afetadas. Um estudo da Companhia de Planejamento do Distrito Federal (Codeplan) ${ }^{6}$ mostra como as regiôes periféricas dessa localidade apresentam maiores números de casos e também maiores taxas de letalidade por contaminação da doença. No mesmo sentido, em nota técnica, a Pontifícia Universidade Católica do Rio de Janeiro (PUC-Rio) ${ }^{7}$ mostrou como a letalidade por Covid-19 é maior entre pessoas pretas e pardas que entre pessoas brancas.

Alguns dos efeitos já diagnosticados da quarentena prolongada especificamente na vida das mulheres são: o aumento da violência doméstica; o aumento da demanda por atividades de cuidados; a redução da produtividade no trabalho para aquelas que estão em regime de trabalho remoto, em especial para as que atuam na área acadêmica; e o aumento do nível de adoecimento

1. DOl: http://dx.doi.org/10.38116/bapi26art6

2. Agradecemos a participação em versão estendida deste estudo de Márcia Vasconcelos, consultora da ONU Mulheres Brasil.

3. Especialista em políticas públicas e gestão governamental na Diretoria de Estudos e Políticas Sociais (Disoc) do Ipea.

4. Técnica de planejamento e pesquisa na Disoc/lpea.

5. 0 Decreto Legislativo ํo 6, de 20 de março de 2020, reconheceu a ocorrência de estado de calamidade pública em decorrência da pandemia ocasionada pela propagação da Covid-19.

6. Disponível em: <http://www.codeplan.df.gov.br/wp-content/uploads/2020/06/Boletim_Codeplan_n10_23.06.20.pdf>.

7. Disponivel em: <http://www.ctc.puc-rio.br/diferencas-sociais-confirmam-que-pretos-e-pardos-morrem-mais-de-covid-19-do-que-brancossegundo-nt11-do-nois/>. 
mental das mulheres (Alencar et al., 2020; UN Women, 2020). Considerando que, na estruturação histórica do mercado de trabalho brasileiro, as mulheres já apresentavam as mais elevadas taxas de desemprego, já eram a maioria no trabalho precário e recebiam os salários mais baixos (Yannoulas, 2002), não surpreende que, no contexto da pandemia, elas tenham sido proporcionalmente muito mais afetadas que os homens com a perda de empregos (Barbosa et al., 2020; Alon et al., 2020). Isso se dá tanto porque esse grupo atua em setores muito afetados pelas medidas de isolamento e pela crise econômica decorrente dele (como comércio e serviços) quanto porque, com o fechamento dos serviços de cuidados de crianças, idosos ou outros correlatos, muitas mulheres precisaram abandonar suas ocupações para garantir o cuidado necessário às populaçóes dependentes, já que ainda recai sobre elas a responsabilidade primeira por tal trabalho.

Como consequência, temos, hoje, a menor taxa de participação feminina no mercado do trabalho dos últimos trinta anos, e a maior parte das mulheres em idade ativa encontrava-se fora da força de trabalho brasileira em junho de 2020 (Hecksher, 2020; Participação..., 2020). Vale destacar, ainda, que, por serem as maiores responsáveis pelos trabalhos na linha de frente de enfrentamento do coronavírus - mais de $70 \%$ dos profissionais que trabalham no atendimento na área de saúde são mulheres (Ipea, no prelo) -, as mulheres também têm o risco ampliado de infecçóes.

Em nota técnica anterior (Pinheiro, Tokarski e Vasconcelos, 2020), que constitui uma versão mais longa deste trabalho, discutimos dois impactos específicos sobre o aumento da vulnerabilidade das trabalhadoras domésticas no contexto da pandemia de Covid-19 no Brasil: o aumento da vulnerabilidade em razão do tipo de trabalho realizado e em razão da realidade de desproteção social quanto a direitos trabalhistas e previdenciários dessa categoria. No entanto, com o agravamento do número de óbitos no Brasil e com o alargamento temporal da situação de distanciamento social, cada vez mais relatos de imposiçôes de condiçóes degradantes são notificados nos sindicatos das trabalhadoras domésticas. Isso nos leva a identificar um terceiro eixo de vulnerabilidade das trabalhadoras domésticas, decorrente das outras duas violaçóes anteriores e com ligação estreita ao histórico escravagista e patriarcal dessa ocupação na sociedade brasileira: a violação sistemática de direitos fundamentais.

Em 2019, no Brasil, cerca de 5,7 milhóes de mulheres estavam ocupadas no trabalho doméstico entre elas, 3,8 milhóes eram mulheres negras, o que corresponde a 14\% das ocupadas no Brasil ou a $18 \%$ das ocupadas negras (diante de $10 \%$ de brancas). O trabalho doméstico representava, em 2019, a terceira categoria profissional que mais emprega mulheres, atrás de serviços sociais e comércio, que englobam uma variedade muito grande de ocupaçóes sob essas grandes denominaçôes (Pinheiro et al., 2019). A quantidade de trabalhadoras empregadas nessa ocupaçáo e a centralidade do emprego doméstico nos trabalhos de cuidados e de reprodução da vida em um país em que, excluídas iniciativas insuficientes de construção de creches, praticamente inexistem políticas públicas nesse sentido, dão a dimensão da importância do trabalho doméstico na organização da sociedade brasileira. Os efeitos da pandemia e de uma quarentena prolongada têm atingido de maneira muito específica essas mulheres, em especial as mulheres negras. A seguir, passamos a discutir tais efeitos na vida das quase 6 milhóes de trabalhadoras domésticas brasileiras. 


\section{AUMENTO DA VULNERABILIDADE DAS TRABALHADORAS DOMÉSTICAS EM FUNÇÃO DO TIPO DE TRABALHO REALIZADO}

O trabalho doméstico caracteriza-se ${ }^{8}$ por ser um serviço prestado de forma subordinada, onerosa, sem finalidades lucrativas, no interior da residência de uma família. Dessa forma, no desempenho de suas funçôes, as trabalhadoras domésticas manipulam constantemente roupas, objetos e fluidos corporais de outras pessoas. As que desempenham o trabalho de babá ou de cuidadora (de idosos, doentes ou pessoas com deficiência) também entram em contato frequentemente com os corpos de seus patrões ou familiares. Agrega-se a essas características o alto grau de subordinação com que esse trabalho é exercido, aliado às poucas informaçóes sobre onde circulam os corpos que transitam no seu ambiente de trabalho. Importa destacar que a idade das trabalhadoras domésticas vem subindo, situação que se configura em outro elemento que confere maior vulnerabilidade para a categoria diante da infecção causada pelo coronavírus (Pinheiro et al., 2019). Todas essas características fazem com que o trabalho doméstico seja uma ocupação extremamente exposta à contaminação entre pessoas.

O isolamento social, como a principal medida adotada para mitigar a transmissão do coronavírus, trouxe como consequência o aumento exponencial do trabalho reprodutivo. A oferta de políticas públicas de cuidados pelo Estado e pelo mercado, que já eram bastante precárias, foi interrompida com o fechamento de creches, escolas, atividades de contraturnos e serviços de acolhimento aos idosos. Ao mesmo tempo, com hospitais lotados, o risco e o medo premente de contaminação fizeram com que as pessoas tendessem a tratar em casa quadros de saúde considerados, por elas, menos graves, o que também ampliou a demanda por cuidados no espaço domiciliar, seja ele realizado de forma gratuita ou remunerada - pelas trabalhadoras domésticas e cuidadoras.

Adiciona-se a esses fatos a iminente necessidade de maior higienização de alimentos, vestimentas e dos ambientes, e tem-se um quadro de sobrecarga dos trabalhos domésticos que chegou a ser medido em alguns países pela Organização das Naçôes Unidas (ONU), indicando que tanto homens quanto mulheres têm vivenciado um aumento na sua carga de trabalho doméstico e de cuidados não remunerados, mas, como já se poderia esperar, esse aumento foi maior para elas que para eles (UN Women, 2020).

As trabalhadoras domésticas converteram-se em profissão da linha de frente do enfrentamento da pandemia, ainda que a essencialidade desse trabalho, no contexto em tela, tenha sido fortemente questionada tanto pelas organizaçóes de trabalhadoras domésticas quanto pelo Ministério Público do Trabalho (MPT), que emitiu parecer definindo que somente poderiam ser considerados trabalhos essenciais aqueles realizados pelas cuidadoras de pessoas dependentes. Segundo a Nota Técnica Conjunta no 4/2020 do MPT, como regra geral, os empregadores deveriam adotar a postura de dispensa remunerada das trabalhadoras domésticas, com exceção para os casos em que sua presença fosse absolutamente necessária. ${ }^{10}$ Uma pesquisa do Instituto Locomotiva ${ }^{11}$ e de universidades públicas brasileiras mostrou ${ }^{12}$ que aquela recomendação do MPT não foi seguida pela maior parte dos empregadores.

8. Art. 10 da Lei Complementar no 150/2015.

9. Disponível em: <https://mpt.mp.br/pgt/noticias/nota-tecnica-4-coronavirus-vale-essa.pdf>.

10. Idosos que moram sozinhos, filhos de pessoas cujas profissões são consideras essenciais e pessoas que necessitam de acompanhamento contínuo. 11. Disponível em: <https://www.ilocomotiva.com.br/single-post/2020/04/23/SBT-BRASIL-39-das-fam\%C3\%ADlias-dispensaram-trabalhadorasdom\%C3\%A9sticas-durante-a-pandemia>.

12. Disponível em: <https://demografiaufrn.net/2020/07/06/projeto-domesticas-ufrn-primeiros-resultados/>. 
Com o passar dos meses, ainda que o país tenha alcançado a marca de mais de 220 mil $^{13}$ pessoas mortas pela Covid-19 no primeiro mês de 2021 e a curva de contaminação siga subindo em diversos estados, setores considerados não essenciais tanto no comércio quanto na prestação de serviços foram reabertos e muitos trabalhadores que até então vinham realizando o trabalho de forma remota foram chamados a retornar em modelo presencial. ${ }^{14}$ Como a maior parte das escolas e creches ainda segue sem funcionamento, é de se esperar que aquelas trabalhadoras que eventualmente tenham sido liberadas tenham que, gradativamente, retornar ao trabalho, ampliando seus riscos no deslocamento - com ônibus cada vez mais lotados - ou no próprio espaço de trabalho. Isso porque os empregadores e residentes dos domicílios têm cada vez mais saído de casa para atividades essenciais, de trabalho ou para atividades náo essenciais e de lazer.

\section{DESPROTEÇÃO SOCIAL E INFORMALIDADE: FRAGILIDADES E INCERTEZAS EM UM CENÁRIO DE PANDEMIA}

O distanciamento social evidentemente implica diversos impactos econômicos e sociais, em especial para aqueles trabalhadores que atuam de forma autônoma e que dependem do trabalho diário para dali retirarem seus sustentos. O caso das trabalhadoras domésticas é um exemplo bastante evidente das dificuldades do distanciamento social, seja no caso das mensalistas, seja no caso das diaristas. E isso se dá por diferentes razóes, entre as quais - e de forma muito importante - o alto grau de desproteção social e informalidade nas relaçóes de trabalho que marca a categoria historicamente.

O nível de informalidade do trabalho doméstico é de tal forma elevado, que significa que, de cada dez mulheres ocupadas nessa profissão, mais de sete não possuem carteira de trabalho assinada, ou seja, não têm acesso a benefícios como seguro-desemprego - caso sejam demitidas - ou auxílio-doença - caso fiquem doentes. ${ }^{15}$ Essa realidade se impóe sobre o conjunto das trabalhadoras, diaristas ou mensalistas, mas o cenário para as primeiras é de ainda mais fragilidade.

É importante ter em mente que nos últimos anos cresceu, de forma muito significativa, a proporção de trabalhadoras domésticas que atuam na modalidade de diária, ou seja, que trabalham em mais de um domicílio, recebendo por cada um desses dias trabalhados. Em 2019, as diaristas já respondiam por $43 \%$ do total de trabalhadoras domésticas, ou quase 2,5 milhóes de mulheres. Segundo a legislação vigente (Lei Complementar no 150/2015), a exigência de formalização de vínculos trabalhistas só se dá àquelas trabalhadoras que exercem suas atividades no mesmo domicílio por três ou mais dias na semana. Para $44 \%$ das trabalhadoras, portanto, não existe proteção legal que assegure a formalização de vínculos de trabalho e não há obrigatoriedade para que os empregadores assinem suas carteiras de trabalho ou contribuam para sua proteção social e trabalhista.

Assim, dado o custo e as dificuldades de contribuição individual, apenas 26\% das diaristas, em 2019, estavam protegidas pela Previdência Social (via carteira de trabalho assinada ou via contribuição individual), sendo que, destas, somente $9 \%$ possuíam carteira assinada e, portanto, direitos trabalhistas. No caso das mensalistas, uma parcela mais expressiva de mulheres contava com carteira de trabalho assinada (41\%, em 2019), o que as assegura, ao menos, o benefício do seguro-desemprego no caso de demissão e do auxílio-doença no contexto da pandemia. É preciso considerar, contudo, que

13. Disponível em: <https://covid.saude.gov.br/>.

14. Exemplo disponível em: <https://www.metropoles.com/brasil/servidor-brasil/servidores-do-ministerio-das-comunicacoes-voltarao-aotrabalho-presencial>.

15. Para mais informações sobre a trajetória da formalização do emprego doméstico no Brasil, ver Pinheiro et al. (2019). 
seguimos falando que muitas das trabalhadoras domésticas mensalistas - quase $60 \%$ - têm seus direitos trabalhistas e previdenciários negados por empregadores, que descumprem a legislação e sofrem pouquíssima fiscalização para alterar esse comportamento (Pinheiro et al., 2019).

Para a esmagadora maioria das trabalhadoras domésticas e cuidadoras, portanto, o futuro, diante da Covid-19, é de incerteza e medo no que se refere à manutenção de algum tipo de renda, caso sejam demitidas ou adoeçam - sem mencionar obviamente as enormes dificuldades de acesso ao sistema de saúde para tratamento, o qual já se encontra colapsado ou parcialmente colapsado em boa parte do país. Importante destacar que, desde 2016, a taxa de formalizaçáo dessa categoria vem caindo de forma expressiva, passando de já reduzidos 33\% para 27\%, em 2019 (Pinheiro et al., 2019), uma diminuiçáo de seis pontos percentuais em apenas quatro anos. Sendo assim, cada vez menos mulheres ocupadas nessa categoria estarão protegidas contra os efeitos atuais e futuros - em termos de manutenção do emprego, da renda e do acesso aos benefícios previdenciários e trabalhistas - da crise sanitária provocada pela Covid-19 e da crise econômica mundial já em curso, e que seguirá por algum tempo.

Nesse sentido, a proposta de auxílio emergencial, elaborada pelo Congresso Nacional e sancionada pelo governo federal por meio da Lei no $13.982 / 2020$, é de grande importância para esse grupo de trabalhadoras. A lei cria a renda básica emergencial, com duração de três meses e valor de R\$ 600 mensais, direcionada aos trabalhadores que, desprotegidos socialmente, se encontram em situação de grande vulnerabilidade no contexto da pandemia da Covid-19. ${ }^{16}$ No início de setembro de 2020, foi anunciado que o auxílio seria prorrogado até dezembro de 2020, mas com o valor de apenas $\mathrm{R} \$ 300$. Essa redução do valor do auxílio gerou uma série de críticas, especialmente quando estudos já mostraram que a existência desse benefício, no valor integral, foi capaz de evitar, em certa medida, uma queda ainda maior que a queda de $9,7 \%$ verificada no produto interno bruto (PIB) brasileiro entre o segundo e o primeiro trimestres de 2020.

Ademais, o auxílio foi capaz de propiciar reduçáo da pobreza via acesso à renda, o que, em muitos casos, possibilitou às famílias, inclusive, contar com uma renda familiar superior àquela com a qual contavam no momento pré-pandemia. Um estudo do Ipea mostra que, entre os domicílios de mais baixa renda, os rendimentos, em julho de 2020, atingiram $124 \%$ do que seriam com as rendas habituais. Mostra também que 6,5\% dos domicílios brasileiros (4,4 milhóes) sobreviveram, em julho de 2020, apenas com os rendimentos do auxílio emergencial, não possuindo qualquer outro tipo de renda (Carvalho, 2020). É evidente que o custo desse benefício é bastante significativo para se manter por longos períodos, mas a manutenção nos níveis de $\mathrm{R} \$ 600$ pode se configurar em uma alternativa do modelo "ganha-ganha" enquanto perdurarem os efeitos da pandemia, ${ }^{17}$ sendo vantajosa tanto para os cidadãos brasileiros quanto para evitar maior recessão econômica.

No grupo de potenciais beneficiários desse auxílio emergencial, estão, evidentemente, as trabalhadoras domésticas, em especial as diaristas, mas também as mensalistas informais. Segundo

16. Os beneficiários devem ser maiores de idade, não podem receber benefícios assistenciais ou previdenciários - à exceção do Programa Bolsa Família - e devem obedecer a determinados critérios de renda familiar e pessoal, quais sejam: a renda familiar per capita mensal não pode exceder meio salário mínimo ou a renda familiar mensal total deve ser de até três salários mínimos. Além disso, o beneficiário não pode ter recebido, em 2018, rendimentos tributáveis superiores a $\mathrm{R} \$ 28.559,70$.

17. Até o encerramento deste texto, em janeiro de 2021, havia oito projetos de lei da Câmara e do Senado e uma proposta de ampliação da Medida Provisória no 1.000/2020 no sentido de estender o período de vigência do auxílio emergencial para 2021. São eles: Projeto de Lei no 5.509/2020; Projeto de Lei no 5.536/2020; Projeto de Lei no 5.650/2020; Projeto de Lei no 5.514/2020; Projeto de Lei no 4.715/2020; Projeto de Lei no 5495/2020; Projeto de Lei no 2.920/2020; e Projeto de Lei no 5.494/2020. 
os dados da Pesquisa Nacional por Amostra de Domicílios (PNAD) 2019, o Brasil contava, naquele ano, com pouco mais de 6 milhóes de homens e mulheres ocupados em emprego doméstico com 18 anos ou mais de idade, sendo que 4,4 milhóes eram trabalhadores domésticos informais - dos quais 4,1 milhóes são mulheres e 2,8 milhóes são mulheres negras. $\mathrm{O}$ auxílio, no caso dessa categoria ocupacional específica, é, portanto, um benefício direcionado para as mulheres, com predominância de mulheres negras, refletindo a composiçáo de sexo e raça da própria categoria.

O auxílio, porém, estabelece um conjunto de outros critérios para acesso ao benefício, para além da condição da informalidade. Considerando todos os critérios exigidos, estimamos que quase 3 milhões de trabalhadores e trabalhadoras domésticas poderiam solicitar acesso ao auxílio emergencial, sendo 2,7 milhóes de mulheres e cerca de 190 mil homens. Esse total corresponde a $67 \%$ dos trabalhadores domésticos que se encontram na informalidade, ou a quase $50 \%$ da categoria como um todo. É, portanto, uma política que possibilita às trabalhadoras manter níveis mínimos de renda e consumo durante o período da pandemia, ao mesmo tempo que permite a manutençáo do isolamento social e a proteçáo para si e para suas famílias diante do crescimento do número de casos de Covid-19 em todo o país e de uma mortalidade que se mantém, há meses, estabilizada em cerca de mil vidas perdidas todos os dias.

Não temos informaçóes que permitam identificar qual percentual desse conjunto de beneficiários potenciais já teve acesso ao benefício - ou ao menos teve o benefício aprovado, ainda que não tenha conseguido recebê-lo. No entanto, considerando que o trabalho doméstico é uma ocupação marcada pela baixa escolaridade, por relaçóes de muita submissão e hierarquia entre empregadores e empregados, e que as trabalhadoras, em geral, atuam de forma isolada, com baixo acesso a outras trabalhadoras ou aos seus próprios sindicatos, é possível supor que a informação de disponibilidade desse auxílio não tenha chegado a todas as trabalhadoras e muitas estejam passando por condiçóes diversas de privação mesmo diante do direito de acessar esse benefício social.

\section{VIOLAÇÃO SISTEMÁTICA DE DIREITOS FUNDAMENTAIS DAS TRABALHADORAS DOMÉSTICAS DURANTE A PANDEMIA DE COVID-19}

Para além dessas duas dimensões de vulnerabilidade do trabalho doméstico e de cuidados remunerados, com o decorrer dos meses, os sindicatos das trabalhadoras domésticas e a Federação Nacional das Trabalhadoras Domésticas (Fenatrad) começaram a relatar um número crescente de denúncias de violação de direitos fundamentais. As denúncias contêm relatos de restrição de mobilidade, cárcere privado, além de jornadas exaustivas e do acúmulo de funçóes para além do acordado contratualmente, constituindo-se em uma terceira e grave situação de aumento da vulnerabilidade decorrente da pandemia de Covid-19.

A alta taxa de informalidade dessa categoria, aliada à pobreza e à desproteção social, coloca as trabalhadoras domésticas entre a decisão de continuar trabalhando e aumentar o risco de se contaminar e contaminar sua família e de parar de trabalhar e perder a renda necessária para o sustento, num contexto em que a recolocação no mercado de trabalho para essas mulheres é um desafio nada simples de ser vencido. Esse dilema cruel lança as trabalhadoras a situações de agudização da vulnerabilidade e violaçáo de direitos fundamentais. Luiza Batista, presidenta da Fenatrad, descreve algumas dessas narrativas de trabalhadoras domésticas que tiveram seus direitos fundamentais violados e que recorreram à federação em busca de reparação e de condições de trabalho mais dignas no período de pandemia. 
Mas há um grupo das que não foram demitidas e procuram o sindicato porque estão vendo seus direitos violados, se sentem muito sobrecarregadas com tarefas que agora são obrigadas a acumular, com carga horária maior porque muitas foram praticamente obrigadas a permanecer no local de trabalho, sem ir para casa. Entende o que está acontecendo? Em vez de liberarem as trabalhadoras, muitos empregadores exigiram que elas permanecessem no local de trabalho, sem ver a família, inclusive. É importante dizer que muitas dessas mulheres são chefes de família, e, apesar de saberem que os empregadores estão abusando, elas se sentem pressionadas a cumprir essa exigência porque dependem dessa renda para alimentar os filhos e para manter a casa. ${ }^{18}$

Uma pesquisa recente da rede internacional Women in Informal Employment: Globalizing and Organizing (Wiego) analisou os riscos crescentes para os trabalhadores informais, em especial os que se dedicam ao trabalho doméstico, em função da extensão da pandemia de Covid-19 em 51 países. ${ }^{19}$ Além de averiguar os tipos de respostas que os países têm adotado, ou deixado de adotar, para os trabalhadores informais, em especial para as trabalhadoras domésticas, o estudo traz que, em situaçóes de emergência como a que vivemos, é comum que sejam abertas brechas para a violação dos direitos Humanos (Wiego, 2020).

No Brasil, a quase total ausência de fiscalização sobre as condições em que esse trabalho é exercido acentua as situações de abusos e violaçóes de direitos.

Tem uma violação mais grave, que inclui essa: é praticamente um cárcere privado, e que inclusive agora estamos denunciando ao Ministério Público, depois de três trabalhadoras aqui de Pernambuco terem decidido enfrentar os patrôes, mesmo sabendo que isso significa ficar sem o emprego em que estão. ${ }^{20}$

Um caso extremo que espelha a mentalidade escravocrata com que boa parte da sociedade brasileira ainda enxerga o emprego doméstico é o caso Mirtes/Miguel. Nesse trágico episódio brasileiro, uma criança perdeu a vida quando, sem escola, teve que acompanhar sua mãe, trabalhadora doméstica, ao emprego. Além de a empregadora descumprir as recomendaçóes de liberação remunerada no período da pandemia, responde atualmente pelo crime de abandono de incapaz, ${ }^{21}$ pois, rompendo o isolamento social para fazer as unhas com uma profissional dentro de sua própria residência, ela deixou uma criança de 5 anos sozinha no elevador enquanto sua mãe, a trabalhadora, passeava com o cachorro da família empregadora.

As denúncias de violação de direitos fundamentais das trabalhadoras domésticas, como cárcere privado, ${ }^{22}$ jornadas exaustivas e restrição de locomoção, são não são raras no Brasil, mas o que tem acontecido diante da situação de emergência sanitária é uma intensificação dessas denúncias. Patróes, com medo de contaminação, restringem a liberdade de locomoção das trabalhadoras ou impóem o cárcere privado. A sobrecarga de trabalho doméstico e a intensificação nas atividades de cuidados e higiene, por sua vez, também levam a situaçóes de jornadas exaustivas e de trabalhos que extrapolam o inicialmente acordado. Vale lembrar que o cárcere, nesse caso, é apenas para as trabalhadoras, uma vez que estas não podem controlar os movimentos de seus empregadores. As taxas de isolamento

18. Disponivel em: <https://fenatrad.org.br/2020/07/31/92/>.

19. Foram analisados países da África, da Ásia e da América Latina.

20. Disponível em: <https://fenatrad.org.br/2020/07/31/92/>.

21. Disponível em: <https://noticias.uol.com.br/cotidiano/ultimas-noticias/2020/07/15/ex-patroa-de-mae-de-miguel-vira-re-por-crime-deabandono-de-incapaz.htm>.

22. Disponível em: <https://www.uol.com.br/universa/noticias/redacao/2018/05/14/mpf-denuncia-carcere-privado-de-empregada-domesticano-rio-de-janeiro.htm>. 
social, que chegaram a atingir o patamar de $62,2 \%$ no final de março de 2020 , recuaram à média de $37,6 \%$ no final de janeiro de 2021, mesmo com o aumento de casos graves e óbitos. ${ }^{23}$ Nesse sentido, as trabalhadoras domésticas ficam mais suscetíveis a se contaminar pelos movimentos de seus empregadores e de suas famílias, além de perderem o controle dos cuidados e da saúde de seus próprios familiares, incluindo crianças e outros dependentes.

\section{CONSIDERAÇÕES FINAIS}

A pandemia e seus efeitos conferiram visibilidade a desproteçôes e desigualdades que historicamente marcam o mercado de trabalho e a sociedade brasileira, além de aprofundá-las em contextos muito particulares. As trabalhadoras domésticas, categoria profissional historicamente marcada pela precarização das condições de trabalho e pela informalidade, vêm sendo especialmente afetadas pelas condiçóes criadas com o advento da pandemia. Por comporem uma categoria que, obviamente, não pode realizar seu trabalho de modo remoto, a essas mulheres restou, no contexto atual, o desemprego ou o exercício de suas atividades profissionais em situação de maior precariedade e vulnerabilidade. Neste estudo, destacamos três pontos a partir dos quais incide essa agudização das condiçóes de vulnerabilidade: o tipo de trabalho realizado; a desproteçáo social da categoria; e a sistemática violaçáo de direitos fundamentais à qual integrantes dessa categoria profissional vêm sendo submetidas. Exemplo de tal vulnerabilidade extrema é o fato de que a primeira morte contabilizada no estado do Rio de Janeiro foi de uma trabalhadora doméstica, que contraiu o vírus de sua empregadora, recém-chegada de viagem à Itália. ${ }^{24}$

Além do contexto específico do trabalho doméstico, ainda recai sobre os corpos das trabalhadoras domésticas toda a gama de vulnerabilidades aprofundadas pela desigualdade social no contexto da Covid-19, como: i) a sobrecarga do trabalho doméstico não remunerado; ii) os maiores índices de letalidade do vírus sobre as pessoas negras, uma vez que majoritariamente a categoria é integrada por mulheres negras; iii) o abastecimento precário de água e saneamento básico em muitas das periferias deste país, o que impede a adoção das medidas mais simples de prevenção ao vírus; iv) o transporte realizado cotidianamente por longas horas em conduçôes lotadas; e v) o acesso a um sistema de saúde que vem sendo paulatinamente precarizado.

Diante da ausência de açóes articuladas de enfrentamento à pandemia ao longo de todos estes meses, o benefício do auxílio emergencial revela-se de grande importância para garantir níveis mínimos de renda e dignidade à enorme parcela da população que dele fez uso, a exemplo das trabalhadoras domésticas. Como mencionado anteriormente, o benefício foi pago por três meses no valor de R \$ 600 e foi estendido até o final de 2020 com o valor de R \$300, sendo que a última parcela foi paga em janeiro de 2021 para os aniversariantes de dezembro não inscritos no Programa Bolsa Família. Isso é preocupante no contexto de abalo do mercado de trabalho e forte crise econômica, além, obviamente, do fato de que a pandemia segue vigente e fazendo muitas vítimas, não sendo improvável imaginar novas ondas de contaminação e movimentos de enrijecimento do isolamento social, assim como já está sendo verificado em países como França e Inglaterra.

Nesse sentido, além das recomendaçôes contidas na Nota Técnica no 4/2020 do MTP mencionadas neste artigo e da manutenção do auxílio emergencial enquanto durarem os efeitos da pandemia em seu valor original, faz-se necessário pensar em outras açóes específicas para as trabalhadoras domésticas.

23. Mais detalhes disponíveis em: <https://mapabrasileirodacovid.inloco.com.br/pt/>.

24. Disponível em: <https://www.bbc.com/portuguese/brasil-51982465>. 
Uma iniciativa importante seria a vacinação prioritária, já que essas mulheres constituem a linha de frente de enfrentamento da pandemia nos domicílios, bem como açóes econômicas específicas para as trabalhadoras domésticas no cenário posterior ao encerramento do estado de calamidade. Em um quadro de recessão econômica como o que vivemos, o desemprego entre mulheres de uma categoria já desprotegida socialmente e informalizada tende a aumentar.

Por fim, é relevante colocar em foco que a ausência de trabalhadoras domésticas e cuidadoras nos domicílios, aliada ao fechamento dos espaços de cuidado públicos e privados à disposição das classes média e alta do país na pandemia, evidenciou a importância dessa categoria na organizaçáo da sociedade brasileira, bem como conferiu luz ao peso e ao tamanho do trabalho doméstico não remunerado realizado cotidianamente por milhóes de mulheres em residências das mais diversas classes sociais. $\mathrm{O}$ reconhecimento do trabalho doméstico não remunerado como estruturante da organização das relaçóes de trabalho produtivo e reprodutivo da sociedade brasileira é, portanto, um passo necessário para a valorizaçáo do trabalho doméstico remunerado.

\section{REFERÊNCIAS}

ALENCAR, J. et al. Políticas públicas e violência baseada no gênero durante a pandemia da Covid-19: açốes presentes, ausentes e recomendadas. Brasília: Ipea, 2020. (Nota Técnica, n. 78).

ALON, T. et al. The impact of Covid-19 on gender equality. Cambridge: NBER, Apr. 2020. (Working Paper Series, n. 26947).

BARBOSA, A. L. et al. Mercado de trabalho e pandemia da Covid-19: ampliação de desigualdades já existentes? Boletim Mercado de Trabalho: Conjuntura e Análise, ano 26, n. 69, jul. 2020.

CARVALHO, S. S. de. Os efeitos da pandemia sobre os rendimentos do trabalho e o impacto do auxílio emergencial: os resultados dos microdados da PNAD Covid-19 de julho. Brasília: Ipea, 2020. (Carta de Conjuntura, n. 48). Disponível em: <https:/www.ipea.gov.br/portal/images/stories/ PDFs/conjuntura/200826_cc48_resultados_pnda_julho.pdf>.

HECKSHER, M. Mercado de trabalho: a queda da segunda quinzena de março, aprofundada em abril. Brasília: Ipea, 2020. (Carta de Conjuntura, n. 47).

IPEA - INSTITUTO DE PESQUISA ECONÔMICA APLICADA. Igualdade de gênero. Boletim de Políticas Sociais: Acompanhamento e Análise, n. 28, no prelo.

PARTICIPAÇÃO das mulheres no mercado de trabalho é a menor em 30 anos, diz Ipea. G1, 7 set. 2020. Disponível em: <https://g1.globo.com/jornal-nacional/noticia/2020/09/07/participacao-dasmulheres-no-mercado-de-trabalho-e-a-menor-em-30-anos-diz-ipea.ghtml> .

PINHEIRO, L. et al. Os desafios do passado no trabalho doméstico do século XXI: reflexóes para o caso brasileiro a partir de dados da PNAD Contínua. Brasília: Ipea, 2019. (Texto para Discussão, n. 2528).

PINHEIRO, L.; TOKARSKI, C.; VASCONCELOS, M. Vulnerabilidades das trabalhadoras domésticas no contexto da pandemia de Covid-19 no Brasil. Brasília: Ipea, 2020. (Nota Técnica, n. 75). 
UN WOMEN. Surveys show that Covid-19 has gendered effects in Asia and the Pacific. New York: UN, Apr. 2020. Disponível em: <https://data.unwomen.org/resources/surveys-show-covid19-has-gendered-effects-asia-and-pacific>. Acesso em: 29 ago. 2020.

WIEGO - WOMEN IN INFORMAL EMPLOYMENT: GLOBALIZING AND ORGANIZING. The impact of Covid-19 laws on informal workers: a review of 51 countries. Law and Informality Insights, n. 2, Aug. 2020.

YANNOULAS, S. C. Dossiê: políticas públicas e relações de gênero no mercado de trabalho. Brasília: Cfemea; FIG/Cida, 2002. 